\title{
PERKEMBANGAN UNDANG-UNDANG PERSAINGAN DALAM KONTEKS HARTA INTELEK DI MALAYSIA
}

\section{(Development of Competition Law in the Context of Intellectual Property in Malaysia)}

\author{
Haliza A. Shukor \\ hliza@usim.edu.my
}

Fakulti Syariah dan Undang-undang, Universiti Sains Islam Malaysia.

Rujukan artikel ini (To cite this article): Haliza A. Shukor (2021). Perkembangan Undang-undang Persaingan dalam konteks harta intelek di Malaysia. Kanun: Jurnal Undang-undang Malaysia, 33(2), 219-238 .http://doi.org. 10.37052/kanun.33(2)no2

\begin{tabular}{|llllll}
\hline $\begin{array}{l}\text { Peroleh: } \\
\text { Received: }\end{array} \quad$ 20/3/2021 & $\begin{array}{l}\text { Semakan: } \\
\text { Revised }\end{array}$ & 22/4/2021 & $\begin{array}{l}\text { Terima: } \\
\text { Accepted: 6/5/2021 }\end{array}$ & $\begin{array}{l}\text { Terbit dalam talian: } \\
\text { Published online }\end{array}$ & 6/7/2021 \\
\hline
\end{tabular}

\begin{abstract}
Abstrak
Undang-undang persaingan telah diperkenalkan di Malaysia sejak tahun 1990-an, namun pada masa itu tidak ada undang-undang khusus mengenai persaingan. Peruntukan berkaitan dengan persaingan terkandung dalam undang-undang yang pelbagai seperti Akta Komunikasi dan Multimedia 1998 dan Akta Suruhanjaya Tenaga 2001. Kerajaan akhirnya mengambil inisiatif untuk memperkenalkan undang-undang khusus mengenai persaingan, yang dikenali sebagai Akta Persaingan 2010 untuk menunjukkan integriti dan komitmen Malaysia terhadap semangat integrasi pasaran di rantau ASEAN. Sejak itu, Malaysia telah mengalami perkembangan undang-undang persaingan, terutamanya berkaitan dengan pelaksanaan undangundang tersebut dalam pelbagai sektor komersil termasuk harta intelek. Selepas sembilan tahun Akta Persaingan 2010 diwujudkan, Suruhanjaya Persaingan Malaysia (MyCC) telah mengeluarkan garis panduan khusus mengenai harta intelek sebagai maklum balas terhadap keperluan komersil semasa dan memenuhi aspirasi yang dinyatakan dalam Garis Panduan Bab 1 Larangan (Perjanjian Anti-
\end{abstract}


Persaingan). Oleh itu, artikel ini bertujuan untuk mengenal pasti dan membincangkan perkembangan undang-undang persaingan di Malaysia berkaitan dengan harta intelek. Artikel ini memaparkan kajian kepustakaan yang menggunakan sumber primer dan sekunder untuk perolehan data. Hasil kajian menunjukkan bahawa walaupun MyCC telah mengeluarkan garis panduan khusus berkaitan dengan harta intelek (Garis Panduan Hak Harta Intelek dan Undang-Undang Persaingan) untuk menyelesaikan isu berkaitan dengan harta intelek, namun beberapa penambahbaikan perlu dibuat agar pelaksanaannya dapat dijalankan secara berkesan.

Kata kunci: Undang-undang persaingan, harta intelek, Garis Panduan Hak Harta Intelek dan Undang-undang Persaingan, MyCC, Malaysia

\section{Abstract}

Competition Competition Law has been introduced in Malaysia since the 1990s, but at that time, there was no specific law on competition. Provisions related to competition were embedded in various legislations, such as the Communications and Multimedia Act 1998 and Energy Commission Act 2001. The government finally took the initiative to introduce specific laws on competition, known as the Competition Act 2010, to show Malaysia's integrity and commitment towards the spirit of market integration in the ASEAN region. Since then, Malaysia has witnessed the development of Competition Law, especially with regard to the implementation of such laws in various commercial sectors, including intellectual property. Nine years after the enactment of the Competition Act 2010, the Malaysia Competition Commission (MyCC) issued specific guidelines on intellectual property in response to the current commercial needs and to meet the aspirations set out in the Guidelines on Chapter 1 Prohibition (Anti-Competition Agreement). Therefore, this article aims to identify and discuss the development of Competition Law in Malaysia related to intellectual property. This article is a literature review that uses primary and secondary sources to obtain data. The result showed that even though MyCC has issued specific guidelines on intellectual property (Guidelines on Intellectual Property Rights and Competition Law) to resolve issues related to intellectual property, some improvements need to be made so that it can be implemented effectively. 
Keywords: Competition law, intellectual property, Guidelines for Intellectual Property Rights and Competition Law, MyCC, Malaysia.

\section{PENDAHULUAN}

Undang-undang persaingan telah wujud sejak ratusan tahun yang lalu di Barat, contohnya Sherman Anti-Trust Act (Akta Sherman 1890) dari Amerika Syarikat (AS) yang wujud sejak tahun 1890. Amerika Syarikat merupakan salah sebuah negara terawal yang mewujudkan undang-undang persaingan dan pembentukan undang-undang tersebut telah dibuat tanpa merujuk mana-mana model tertentu (Gerber, 2010: 125). Walaupun Akta Sherman 1890 digunakan sebagai rujukan untuk penyelesaian masalah yang berkaitan dengan amalan perdagangan, masalah persaingan yang berkaitan dengan harta intelek juga menjadi salah satu isu utama yang diputuskan oleh Akta Sherman 1890 dan juga pihak berkuasa berkaitan dengan persaingan di AS. Menelusuri susur galur kewujudan Akta Sherman 1890, dapat difahami bahawa kontroversi antara undang-undang persaingan dan harta intelek yang wujud pada tahun 1910 timbul akibat ketidakseimbangan penguatkuasaan Undangundang Persaingan dan harta intelek di AS pada masa itu (Furse, 2008:1). Oleh yang demikian, senarai larangan beberapa amalan pelesenan harta intelek telah diperkenalkan oleh badan penguat kuasa persaingan di AS pada waktu itu yang dinamakan "the Nine No-No's". Senarai tersebut berfungsi sebagai undang-undang yang ketat untuk semua jenis hubungan perniagaan termasuklah sembilan amalan pelesenan harta intelek yang dianggap sebagai antipersaingan jika dimasukkan sebagai klausa dalam kontrak pelesenan harta intelek. Antara amalan pelesenan harta intelek yang tersenarai dalam "the Nine No-No's" termasuklah mensyaratkan pemegang lesen membeli bahan daripada pemberi lesen walaupun barang tersebut tiada kaitan dengan paten, pelesenan semula secara eksklusif oleh pemegang lesen kepada pemberi lesen, menyekat hak pembelian produk dalam urusan penjualan semula produk, menyekat kemampuan pemegang lesen untuk berurusan dengan produk yang di luar skop paten, kewajipan terhadap pemegang lesen untuk memberikan pelesenan secara pakej, mengenakan royalti pada produk yang tidak ada kaitan dengan paten yang dilesenkan, mengenakan sekatan penggunaan produk yang mengandungi proses yang dipatenkan kepada pemegang lesen dan menetapkan jumlah harga minimum jualan semula produk atau 
paten yang dilesenkan (Gilbert \& Shapiro, 1997: 284-286). Senarai "the Nine No-No 's" tidak bertahan dan digantikan dengan Antitrust Guidelines for the Licensing of Intellectual Property (Garis Panduan Persaingan untuk Pelesenan Harta Intelek) yang dikeluarkan pada 6 April 1995. Garis Panduan tersebut telah ditambah baik dan diganti dengan Garis Panduan Persaingan untuk Pelesenan Harta Intelek yang dikeluarkan pada 12 Januari 2017 (Leslie, 2011: 43-45). Keadaan ini menunjukkan bahawa terdapat keperluan mewujudkan garis panduan khusus Undangundang Persaingan bagi mengatur amalan perdagangan sektor komersial termasuk harta intelek.

Di ASEAN misalnya, para sarjana menyatakan keprihatinan mereka terhadap pembentukan undang-undang persaingan dalam kalangan negara-negara membangun. Menurut Maskus (2001: 472), Undangundang Persaingan dianggap "baharu dan rumit untuk negara-negara membangun". Sementara itu, Yijun Tian (2009: 354) berpendapat bahawa pengawal selia undang-undang persaingan di negara-negara membangun perlu membentuk undang-undang persaingan yang terkehadapan bagi memenuhi keperluan dalam konteks harta intelek. Cendekiawan lain seperti Janis (2005: 786) lebih memilih pendekatan "standard minimum" untuk pelaksanaan Undang-undang Persaingan berkaitan dengan harta intelek bagi negara-negara membangun sementara Nguyen (2010: 244) berpendapat bahawa pembangunan garis panduan persaingan bagi harta intelek perlu disesuaikan dengan perkembangan sosioekonomi negara membangun tertentu untuk memastikannya selaras dengan keperluan domestik. Menurut Khadijah (2020: 156) pula, dengan adanya Garis Panduan Hak Harta Intelek dan Undang-undang Persaingan yang dikeluarkan oleh MyCC, keperluan bagi menangani isu-isu berkaitan dengan harta intelek yang tidak dinyatakan secara jelas dalam Garis Panduan Bab 1 Larangan (Perjanjian Anti-Persaingan) dan juga Garis Panduan Bab 2 Larangan (Penyalahgunaan Kedudukan Dominan) dapat dipenuhi.

Oleh yang demikian, artikel ini akan mengenal pasti dan membincangkan tentang perkembangan Undang-undang Persaingan di Malaysia dari awal pelaksanaannya hingga kini dengan difokuskan khusus untuk bidang harta intelek. Perbincangan dalam artikel ini dimulai dengan latar belakang undang-undang persaingan di Malaysia dan diikuti dengan penerangan berkaitan dengan garis panduan yang dikeluarkan oleh MyCC, termasuk kes-kes yang telah diputuskan oleh MyCC, Tribunal Rayuan 
Persaingan dan juga Mahkamah Tinggi. Perbincangan selanjutnya akan mengkhusus pada perkembangan undang-undang persaingan berkaitan dengan harta intelek di Malaysia yang meliputi perkara berkaitan inti pati Garis Panduan Hak Harta Intelek dan Undang-undang Persaingan. Bahagian akhir artikel ini akan memberikan kesimpulan dan cadangan untuk pemantapan undang-undang persaingan dalam konteks harta intelek di Malaysia.

\section{LATAR BELAKANG UNDANG-UNDANG PERSAINGAN DI MALAYSIA}

Secara amnya, keputusan kerajaan Malaysia untuk melaksanakan program penswastaan merupakan titik tolak yang telah mendorong pewujudan undang-undang persaingan. Program penswastaan yang dimulakan oleh kerajaan akibat krisis ekonomi yang berlaku pada tahun 1985 hingga 1987 bertujuan untuk menstabilkan kemerosotan ekonomi pada masa itu kerana penswastaan dianggap dapat meningkatkan kecekapan dan mengurangkan monopoli dalam pasaran. Oleh sebab tidak ada undangundang persaingan yang khusus untuk mengatur hal-hal yang melibatkan aktiviti perdagangan, rujukan tentang perdagangan dan amalan perniagaan pada waktu itu dibuat melalui pelbagai undang-undang seperti, Akta Perihal Dagangan 1972 (Akta 87) dan Akta Perlindungan Pengguna 1999 (Akta 599). Akta 87 menyebut perkara yang berkaitan dengan perdagangan, sementara Akta 599 memberikan perlindungan kepada pengguna dalam aktiviti perniagaan mereka. Walau bagaimanapun, Akta Perihal Dagangan 1972 dimansuhkan dan digantikan dengan Akta Perihal Dagangan 2011 (Akta 730) yang dikuatkuasakan pada bulan November 2011 (Nasaruddin \& Haniff, 2016: 27).

Usul berkaitan dengan keperluan mewujudkan undang-undang persaingan yang khusus telah dibuat oleh Kementerian Perdagangan Dalam Negeri, Koperasi dan Kepenggunaan (KPDNKK) pada tahun 1993 namun ditolak kerana penubuhannya dianggap tidak dapat menyokong dasar kerajaan sedia ada pada waktu itu, iaitu Dasar Ekonomi Baru (DEB). DEB pada asasnya bertujuan untuk menyeimbangkan ekonomi antara kumpulan kaum di Malaysia, iaitu Bumiputera, Melayu dan bukan Bumiputera. Selain itu, kewujudan undang-undang persaingan yang khusus dianggap tidak relevan kerana undang-undang lain mampu memberikan penyelesaian berkaitan dengan isu persaingan sekiranya 
diperlukan. Pada waktu itu, sektor tenaga dan komunikasi telah mewujudkan peruntukan berkaitan dengan persaingan di sektor mereka. Sebagai contoh, seksyen 133 Akta Komunikasi dan Multimedia 1998 (Akta 588) memperuntukkan larangan tingkah laku antipersaingan yang "secara substansial mengurangkan persaingan dalam sektor komunikasi dan multimedia." Begitu juga dalam sektor tenaga apabila Suruhanjaya Tenaga diminta untuk memantau persaingan seperti yang diperuntukkan di bawah seksyen 14 (h) Akta Suruhanjaya Tenaga 2001 (Akta 610). Beberapa siri perbincangan telah dibuat dan akhirnya setelah pertemuan dengan ahli-ahli negara ASEAN melalui Deklarasi ASEAN (Bali) Concorde II 2003 pada tahun 2003, Malaysia mengambil pendekatan untuk memperkenalkan undang-undang persaingan nasional yang bertujuan untuk menikmati faedah yang dibawa oleh pasaran ASEAN dan juga antarabangsa. Oleh itu, pada tahun 2009, Rang Undang-undang Amalan Perdagangan Adil 2006 (RUU Amalan Perdagangan Adil 2006) telah disediakan yang kemudian dikenali sebagai Rang Undang-undang Persaingan 2009 (RUU Persaingan 2009). Beberapa peruntukan yang sebelum ini dimasukkan dalam RUU Amalan Perdagangan Adil 2006 seperti amalan perdagangan yang tidak adil dan rejim pengecualian juga telah diubah suai oleh RUU Persaingan 2009 (Nasaruddin \& Haniff, 2016: 47). Pada tahun 2010, undang-undang persaingan nasional diperkenalkan, iaitu Akta Persaingan 2010 (Akta 712) yang berkuat kuasa pada Januari 2012.

\section{AKTA PERSAINGAN 2010 DAN GARIS PANDUAN}

Akta 712 yang mula berkuat kuasa pada Januari 2012 telah menetapkan beberapa objektif, iaitu meningkatkan pembangunan ekonomi dengan menggalakkan dan melindungi proses persaingan. Akta 712 mengandungi 67 bahagian yang dibahagikan kepada enam bahagian, seperti yang berikut: Bahagian I pada awal, Bahagian II tentang amalan antipersaingan, Bahagian III tentang penyiasatan dan penguatkuasaan, Bahagian IV tentang keputusan oleh suruhanjaya, Bahagian V Tribunal Rayuan Persaingan dan Bahagian VI tentang Umum. Skop Akta 712 meliputi semua aktiviti komersial, namun tidak termasuk aktiviti komersial yang secara langsung atau tidak langsung dalam perjalanan kuasa kerajaan, aktiviti komersial yang dijalankan berasaskan prinsip perpaduan dan aktiviti komersial yang melibatkan pembelian barang atau perkhidmatan yang bukan bagi maksud untuk menawarkan barangan 
atau perkhidmatan sebagai sebahagian daripada suatu aktiviti ekonomi. Hal ini diperuntukkan dengan jelas dalam seksyen 3(1) dan seksyen 3(4) Akta 712. Seksyen 3(3) Akta 712 pula menetapkan bahawa peruntukan tidak terpakai untuk aktiviti komersial yang disenaraikan dalam Jadual Pertama. Pada awal pengenalan Akta 712, hanya dua sektor yang tersenarai dalam Jadual Pertama, iaitu sektor komunikasi dan tenaga kerana masing-masing telah mempunyai peruntukan persaingan di bawah Akta 588 dan juga Akta 610. Walau bagaimanapun, pada tahun 2014, sektor yang tersenarai dalam Jadual Pertama Akta 712 telah bertambah apabila Akta Pembangunan Petroleum 1974 (Akta 144) dan Peraturanperaturan Petroleum 1974 telah dimasukkan dalam Jadual Pertama. Pada tahun 2015, sektor penerbangan juga tersenarai dalam Jadual Pertama yang menjadikan sejumlah empat sektor tersenarai dalam Jadual Pertama sehingga kini. Selain itu, Akta 712 juga memperuntukkan larangan berkaitan dengan amalan antipersaingan yang diperuntukkan dalam Bahagian II, iaitu larangan berkaitan dengan perjanjian antipersaingan dan penyalahgunaan kedudukan dominan. Larangan berkaitan dengan perjanjian antipersaingan diperuntukkan dalam seksyen 4, manakala penyalahgunaan kedudukan dominan diperuntukkan dalam seksyen 10 Akta 712.

Bagi tujuan melaksanakan peruntukan yang terkandung dalam Akta 712, beberapa garis panduan telah dikeluarkan oleh MyCC sejajar dengan fungsi MyCC yang diperuntukkan dalam Akta Suruhanjaya Persaingan 2010 (Akta 713) melalui seksyen 16. Garis panduan yang telah dikeluarkan oleh MyCC adalah seperti yang berikut; Garis Panduan Bab 1 Larangan: Perjanjian Anti Persaingan, Garis Panduan Bab 2 Larangan: Penyalahgunaan Kedudukan Dominan, Garis Panduan Penalti Kewangan, Garis Panduan Definisi Pasaran, Garis Panduan Rejim Kelonggaran, Garis Panduan Prosedur Aduan dan Garis Panduan Hak Harta Intelek dan Undang-undang Persaingan. Semua garis panduan yang dikeluarkan oleh MyCC mempunyai peranan dan fungsi tertentu. Sebagai contoh, Garis Panduan Bab 1 Larangan: Perjanjian Anti Persaingan digunakan untuk memberikan rujukan berkaitan dengan tafsiran perjanjian antipersaingan di bawah Bab 1 Bahagian II Akta 712, manakala Garis Panduan Bab 2 Larangan: Penyalahgunaan Kedudukan Dominan menerangkan tentang tingkah laku perusahaan yang tergolong dalam salah guna kedudukan dominan. Garis panduan berkaitan dengan definisi pasaran digunakan untuk membantu pentafsiran istilah "pasaran" sementara Garis Panduan 
Penalti Kewangan digunakan untuk membantu MyCC untuk menilai denda kewangan yang dikenakan kepada perusahaan akibat perbuatan melanggar peruntukan Akta 712. Garis Panduan Rejim Kelonggaran pula menumpukan pada penetapan kerangka kerja untuk memberikan kelonggaran kepada perusahaan yang melanggar seksyen 4(2) Akta 712 berkaitan dengan perjanjian antipersaingan, manakala Garis Panduan Prosedur Aduan digunakan sekiranya terdapat laporan berkaitan dengan tingkah laku antipersaingan dalam perusahaan. Garis Panduan Hak Harta Intelek dan Undang-undang Persaingan pula mengkhusus pada menerangkan aplikasi peruntukan Akta 712 kepada pemilik harta intelek.

\section{PENGUATKUASAAN UNDANG-UNDANG PERSAINGAN OLEH MYCC DALAM PELBAGAI SEKTOR KOMERSIAL}

MyCC merupakan badan yang bertanggungjawab untuk melaksanakan peruntukan yang terkandung dalam Akta 712. Tanggungjawab badan ini dapat dilihat melalui seksyen 16 Akta 713 yang memberikan mandat kepada MyCC untuk menjalankan fungsi terasnya seperti advokasi, peraturan dan penguatkuasaan undang-undang persaingan di Malaysia. Dalam menjalankan fungsinya sebagai penguat kuasa undang-undang persaingan di Malaysia, MyCC telah melaksanakannya tugasnya secara berperingkat, yang dimulai dengan pendekatan mendidik dan kemudian mengenakan denda kewangan untuk kes pelanggaran peruntukan larangan yang terkandung dalam Akta 712. Kes penetapan harga oleh Cameron Highland Floriculturist Association (CHFA) merupakan kes terawal berkaitan dengan pelanggaran seksyen 4(2) Akta 712, namun tidak ada penalti kewangan yang dikenakan ${ }^{1}$ kerana MyCC mengambil pendekatan mendidik disebabkan Akta 712 masih baru diperkenalkan pada waktu itu.

Selepas kes pelanggaran oleh CHFA, MyCC telah mula mengenakan penalti kewangan terhadap pelbagai sektor komersial kerana pelanggaran seksyen 4 dan seksyen 10 Akta 712 seperti sektor penerbangan, pengeluar ais, Persatuan Bakeri dan Persatuan Bakeri Sibu dan perkhidmatan insurans. ${ }^{2}$ Tahun 2016 pula menunjukkan terdapat beberapa kes yang didengar di hadapan Tribunal Rayuan Persaingan, iaitu kes yang melibatkan Malaysian Airline System Berhad, AirAsia Berhad dan Air

\footnotetext{
1 No. Kes: MyCC/0003/2012(ACA). https://www.mycc.gov.my.

2 Kes-kes ini boleh diakses di laman sesawang MyCC iaitu https://www.mycc.gov.my.
} 
Asia X Sdn Bhd, ${ }^{3}$ Prompt Dynamics Sdn Bhd ${ }^{4}$ dan juga My EG Services Bhd \& My EG Commerce Sdn Bhd. ${ }^{5}$ Selain itu, perkembangan baru-baru ini menunjukkan peningkatan kes yang memohon semakan kehakiman oleh Mahkamah Tinggi. Contohnya, pada tahun 2018, hanya satu kes yang membuat permohonan untuk semakan kehakiman di Mahkamah Tinggi, iaitu kes Malaysian Airline System Berhad, AirAsia Berhad dan Air Asia X Sdn Bhd. ${ }^{6}$ Namun begitu, pada tahun 2019 jumlahnya meningkat menjadi tiga kes, iaitu kes My EG Services Bhd \& My EG Commerce Sdn Bhd, ${ }^{7}$ kes Wealthy Care Consortium Sdn $\mathrm{Bhd}^{8}$ dan kes Lee Ting San Lorry Transport. ${ }^{9}$

\section{UNDANG-UNDANG PERSAINGAN DALAM PERKARA BERKAITAN DENGAN HARTA INTELEK}

Objektif undang-undang persaingan dan undang-undang harta intelek adalah untuk meningkatkan kesejahteraan pengguna melalui persaingan dan inovasi. Namun demikian, pendekatan yang diguna pakai dalam kedua-dua undang-undang bagi mencapai objektif tersebut adalah berbeza antara satu sama lain sehingga menyebabkan wujud ruang hubung kait antara undang-undang persaingan dan undang-undang harta intelek (United Nations, 2016). Menurut Hovenkamp (2005: 2-4), undang-undang persaingan menyediakan peraturan yang mencegah apaapa halangan untuk memasuki pasaran dengan alasan bahawa undangundang persaingan menggalakkan lebih banyak produk ditawarkan di pasaran dengan harga yang kompetitif bagi mewujudkan persaingan.

3 Rayuan Tribunal Persaingan No. TRP 1-2016. https://www.mycc.gov.my ( akses 8 Februari 2021).

4 Rayuan Tribunal Persaingan No. TRP 2-2016. https://www.mycc.gov.my ( akses 8 Februari 2021).

5 Rayuan Tribunal Persaingan No. TRP 3-2016. https://www.mycc.gov.my ( akses 8 Februari 2021).

6 Permohonan Semakan Kehakiman WA-25-82-05/2016. https://www.mycc.gov.my ( akses 8 Februari 2021).

7 Permohonan Semakan Kehakiman WA-25-81-03/2018. https://www.mycc.gov.my ( akses 8 Februari 2021).

8 Permohonan Semakan Kehakiman PA-25-94-10/2018. https://www.mycc.gov.my ( akses 8 Februari 2021).

9 Permohonan Semakan Kehakiman WA-25-95-10/2018. https://www.mycc.gov.my ( akses 8 Februari 2021). 
Undang-undang Persaingan memenuhi objektif kesejahteraan pengguna dengan mengatur kegiatan komersial melalui persaingan yang adil dan membanteras monopoli. Dengan cara itu, pengusaha perniagaan akan bersaing sesama mereka dari segi harga, kualiti barangan dan perkhidmatan. Oleh yang demikian, pengguna mempunyai pelbagai pilihan barang dan perkhidmatan dengan harga yang lebih berpatutan.

Dari perspektif undang-undang harta intelek, kesejahteraan pengguna dapat dicapai dengan cara memberikan hak monopoli sementara kepada pemilik harta intelek apabila harta intelek telah berdaftar. Sebagai contoh, pelesenan harta intelek merupakan salah satu hak monopoli sementara yang diberikan undang-undang harta intelek kepada pemilik harta intelek (Caro de Sousa, Pedro, 2018: 1-3). Melalui pelesenan harta intelek, teknologi atau produk yang dihasilkan dapat disediakan di pasaran untuk keperluan pengguna. Oleh itu, ruang hubung kait antara undang-undang persaingan dan undang-undang harta intelek dapat dilihat apabila undang-undang persaingan melarang perbuatan monopoli dalam kalangan pengusaha perniagaan, manakala undang-undang harta intelek memberikan monopoli sementara kepada pemilik harta intelek. Dalam masa yang sama, kedua-dua undang-undang tersebut bermatlamat untuk meningkatkan kesejahteraan pengguna.

Walaupun pihak penguat kuasa undang-undang persaingan melihat aktiviti pelesenan harta intelek sebagai aktiviti yang bukan bersifat antipersaingan, namun wujud kebimbangan terhadap kemungkinan berlakunya pelanggaran undang-undang persaingan oleh pemilik harta intelek seperti memeterai perjanjian pelesenan yang mengandungi klausa antipersaingan dan juga penyalahgunaan kedudukan dominan (perenggan 3.3 Garis Panduan Hak Harta Intelek dan Undang-undang Persaingan). Selain itu, pemilikan harta intelek oleh sesebuah perusahaan juga dianggap dominan dan sekali gus aktiviti dan tingkah laku perusahaan tersebut akan menjadi perhatian pihak penguat kuasa undang-undang persaingan (Stakheyeva, 2018: 4).

Atas dasar inilah, maka garis panduan khusus berkaitan dengan harta intelek amat diperlukan agar dapat menjelaskan ruang lingkup yang boleh dilaksanakan oleh undang-undang persaingan bagi perkara yang berkaitan dengan harta intelek. Perbincangan lanjut berkaitan dengan Garis Panduan Hak Harta Intelek dan Undang-undang Persaingan adalah seperti yang berikut. 


\section{Garis Panduan Hak Harta Intelek dan Undang-Undang Persaingan}

Di Malaysia, salah satu usaha yang diambil oleh MyCC untuk memantapkan pelaksanaan undang-undang persaingan dalam bidang harta intelek adalah dengan mengeluarkan Garis Panduan Hak Harta Intelek dan Undang-undang Persaingan yang telah digazetkan pada 5 April 2019. Kewujudan Garis Panduan Hak Harta Intelek dan UndangUndang Persaingan selaras dengan hasrat MyCC yang terkandung dalam Garis Panduan Bab 1 Larangan (Perjanjian Anti-Persaingan) untuk mewujudkan garis panduan berasingan berkaitan dengan harta intelek.

Secara umumnya, Garis Panduan Hak Harta Intelek Dan Undang-undang Persaingan mengandungi 8 perenggan utama yang bertujuan memberikan panduan berkaitan dengan pendekatan yang akan diambil oleh MyCC tentang isu persaingan dan harta intelek. Walau bagaimanapun, perenggan 1 Garis Panduan Hak Harta Intelek dan Undang-undang Persaingan menyatakan bahawa garis panduan ini perlu dibaca bersama-sama dengan garis panduan lain yang telah dikeluarkan sebelum ini oleh MyCC seperti yang telah dibincangkan sebelum ini. Selain itu, Garis Panduan Hak Harta Intelek dan Undang-undang Persaingan mengambil maklum perihal ruang hubung kait antara undang-undang persaingan dan juga harta intelek yang dinyatakan secara khusus melalui perenggan 3. Menurut Garis Panduan Hak Harta Intelek dan Undang-undang Persaingan tersebut, walaupun hak eksklusif diberikan kepada pemilik harta intelek oleh undang-undang harta intelek, hak eksklusif tersebut boleh mempengaruhi pasaran dan beberapa tingkah laku pemilik harta intelek dalam beberapa keadaan boleh menyebabkan pelanggaran undang-undang persaingan. Sebagai contoh, pemilik harta intelek boleh mencapai kedudukan dominan di pasaran sehingga mereka mampu menentukan terma dan syarat yang tidak adil kepada pemain pasaran yang lain yang akhirnya menjejaskan pengguna (perenggan 3.2 Garis Panduan Hak Harta Intelek dan Undangundang Persaingan).

Selain itu, Garis Panduan Hak Harta Intelek dan Undang-undang Persaingan juga mengenal pasti mekanisme lain yang diguna pakai untuk mengawal penyalahgunaan hak harta intelek oleh pemiliknya seperti Akta Paten 1983, Akta Hak Cipta 1987 dan juga Akta Reka Bentuk Perindustrian 1996. Akta yang disebut di atas memperuntukkan klausa tidak sah yang dianggap sebagai salah satu bentuk penyalahgunaan harta intelek dan juga peruntukan berkaitan dengan pelesenan wajib sekiranya pemilik harta intelek enggan melesenkan harta inteleknya tanpa sebab 
yang munasabah (perenggan 3.5 dan 3.6 Garis Panduan Hak Harta Intelek dan Undang-undang Persaingan).

Perenggan 4 Garis Panduan Hak Harta Intelek dan Undang-undang Persaingan menyenaraikan dan mendefinisikan pasaran yang berkaitan dengan harta intelek, iaitu pasaran barang, teknologi dan atau penyelidikan dan pembangunan. Pasaran tersebut merupakan tambahan pada pasaran yang sedia ada yang telah diperuntukkan dalam Garis Panduan Definisi Pasaran. Melalui perenggan 4, MyCC menjelaskan bahawa pasaran berkaitan dengan barang dalam konteks harta intelek bermaksud produk akhir ataupun produk yang mengandungi harta intelek. Proses atau teknologi yang mengandungi harta intelek pula dianggap sebagai pasaran berkaitan dengan teknologi, manakala pengetahuan (know-how) yang menghasilkan harta intelek dikategorikan sebagai pasaran berkaitan dengan inovasi atau penyelidikan dan pembangunan. Penerangan lanjut berkaitan dengan setiap pasaran tersebut juga dibuat oleh MyCC berserta ilustrasi bagi tujuan pemahaman yang lebih efektif dalam kalangan pemilik harta intelek.

Bagi tujuan untuk memberikan panduan berkaitan dengan tingkah laku pemilik harta intelek yang mempunyai potensi pelanggaran Bab 1 dan Bab 2 dalam Akta 712, iaitu larangan berkaitan dengan perjanjian antipersaingan dan juga penyalahgunaan kedudukan dominan, hal ini dijelaskan secara panjang lebar dalam perenggan 6 dan 8. Panduan berkaitan dengan pelaksanaan kedua-dua larangan tersebut juga ada dibuat secara berasingan dalam Garis Panduan Bab 1 Larangan (Perjanjian Anti-Persaingan) dan Garis Panduan Bab 2 Larangan (Penyalahgunaan Kedudukan Dominan). Kedua-dua Garis Panduan tersebut perlu dibaca bersama-sama dengan Garis Panduan Hak Harta Intelek dan Undangundang Persaingan sekiranya terdapat keperluan. Hal ini diperuntukkan dalam perenggan 5 Garis Panduan Hak Harta Intelek dan Undang-undang Persaingan.

Perenggan 6 Garis Panduan Hak Harta Intelek dan Undang-undang Persaingan menerangkan tentang pendekatan yang diambil oleh MyCC berkaitan dengan aplikasi seksyen 4, Akta 712 terhadap pemilik harta intelek berdasarkan dua jenis perjanjian pelesenan, iaitu perjanjian mendatar pelesenan harta intelek dan perjanjian menegak pelesenan harta intelek. Kedua-dua perjanjian mendatar dan menegak perlu dibezakan kerana kedua-duanya mendatangkan implikasi yang berbeza dari sudut pandang undang-undang persaingan secara amnya dan Akta 
712 secara khususnya. Melalui perenggan 6 itu juga, senarai klausa yang sering dimasukkan dalam perjanjian pelesenan dikenal pasti, antaranya termasuklah klausa berkaitan dengan penetapan harga, sekatan geografi, pelesenan eksklusif, urus niaga eksklusif dan juga ikatan. Perenggan 6 juga memberikan contoh situasi yang boleh menjadikan klausa tersebut menyalahi Akta 712.

Sekiranya pemilik harta intelek mendapati bahawa ia telah memeterai perjanjian yang bersifat antipersaingan, pelepasan liabiliti boleh dipohon daripada pihak MyCC. Perkara ini selaras dengan seksyen 5 Akta 712 yang memperuntukkan pelepasan liabiliti khusus untuk larangan berkaitan dengan perjanjian antipersaingan. Oleh itu, perenggan 5 Garis Panduan Hak Harta Intelek dan Undang-undang Persaingan juga menerangkan permohonan pelepasan liabiliti yang boleh dibuat oleh pemilik harta intelek secara individu atau secara blok yang boleh dikemukakan kepada pihak MyCC sekiranya memenuhi syarat-syarat di bawah seksyen 5 Akta 712.

Selain larangan memeterai perjanjian yang bersifat antipersaingan, penyalahgunaan kedudukan dominan juga merupakan salah satu larangan yang disebut dalam Akta 712. Penjelasan berkaitan dengan pendekatan yang diambil oleh MyCC untuk menentukan pelanggaran berkaitan dengan penyalahgunaan kedudukan dominan dalam seksyen 10 Akta 712 oleh pemilik harta intelek dibuat dalam perenggan 8 Garis Panduan Hak Harta Intelek dan Undang-undang Persaingan. Perenggan 8 Garis Panduan tersebut menyatakan bahawa pemilikan harta intelek tidak semestinya memberikan kuasa pasaran kepada pemiliknya. Berlakunya hal seperti ini, dalam keadaan tertentu, apabila pemilik harta intelek mempunyai hak eksklusif terhadap harta inteleknya. Hak eksklusif tersebut dengan sendirinya menjadi halangan bagi pesaing lain untuk bersaing dalam pasaran. Perenggan 8 Garis Panduan tersebut menjelaskan tentang situasi tingkah laku seorang pemilik harta intelek yang dominan yang mempengaruhi pasaran dan sekali gus melanggar seksyen 10 Akta 712. Antara tingkah laku yang tergolong dalam penyalahgunaan kedudukan dominan yang disebut dalam garis panduan tersebut adalah dengan mengenakan harga belian atau jualan yang tidak adil atau syarat perdagangan yang tidak adil kepada pembekal atau pelanggan. Sebagai contoh, mengenakan harga yang tidak berpatutan atau berlebihan, dan mengenakan bayaran royalti terhadap paten selepas tamat tempoh perlindungan undang-undang paten tersebut. Selain itu, perbuatan 
membataskan atau mengawal pengeluaran, saluran keluar pasaran atau capaian pasaran, pembangunan teknikal atau teknologi atau pelaburan sehingga memudaratkan pengguna juga merupakan tingkah laku yang dilarang di bawah seksyen 10 Akta 712 .

Keengganan pemilik harta intelek untuk melesenkan harta inteleknya tanpa sebab munasabah, mengenakan syarat yang berlainan untuk transaksi yang setara, menjadikan pengikatan kontrak tertakluk pada penerimaan oleh pihak lain akan syarat tambahan yang tiada kaitan dengan kontrak, berkelakuan seakan-akan pemangsa terhadap pesaing atau membeli barangan perantaraan atau sumber yang terhad bekalannya oleh pihak yang dominan tanpa justifikasi komersial yang munasabah juga merupakan tingkah laku yang membolehkan pemilik harta intelek dikenakan penalti kerana melanggar peruntukan dalam Akta 712. Selain tingkah laku yang disebut di atas, terdapat beberapa tingkah laku lain yang boleh menyebabkan pelanggaran seksyen 10 Akta 712. Antaranya termasuklah himpitan margin, potongan dan rebat serta keengganan untuk melesenkan paten standard Fair, Reasonable and Non-discriminatory (FRAND). Beberapa ilustrasi juga dimuatkan dalam perenggan 8 untuk memberikan gambaran jelas jenis tingkah laku yang menyalahi Akta 712 . Perenggan 8 ini merupakan perenggan terakhir yang terkandung dalam Garis Panduan Hak Harta Intelek dan Undang-undang Persaingan.

\section{ISU BERKAITAN DENGAN UNDANG-UNDANG PERSAINGAN DAN HARTA INTELEK}

Kewujudan Garis Panduan Hak Harta Intelek dan Undang-undang Persaingan yang dikeluarkan oleh MyCC jelas menunjukkan bahawa Malaysia juga tidak ketinggalan untuk memastikan pelaksanaan undangundang persaingan berkembang meliputi perkara yang berkaitan dengan harta intelek. Satu kajian telah dijalankan oleh MyCC, iaitu Kajian Pasaran bagi Sektor Farmaseutikal dan telah dimuatkan dalam dokumen yang dikenali sebagai Market Review on Priority Sector under Competition Act 2010 (Pharmaceutical Sector). Hasil daripada kajian pasaran tersebut menunjukkan bahawa persilangan antara undang-undang paten dan persaingan adalah nyata yang memerlukan semakan semula Akta Paten 1983 (Akta 291) terutamanya di bawah seksyen 45 ( Kajian Pasaran bagi Sektor Farmaseutikal, 2017: 144). Seksyen 45 Akta 291 memperuntukkan perkara berkaitan dengan klausa tidak sah dalam kontrak pelesenan 
paten. Menurut seksyen 45 tersebut, mana-mana klausa atau syarat dalam kontrak lesen adalah tidak sah sekiranya klausa atau syarat tersebut yang dikenakan kepada pemegang lesen, dalam bidang perindustrian atau komersial, ialah sekatan yang tidak berasal daripada hak yang diberikan oleh Bahagian IX Akta 291 kepada pemilik paten.

Subseksyen (b) seksyen 45 Akta 291 membenarkan klausa yang mensyaratkan pemegang lesen paten menjauhi semua tindakan yang mampu menjejaskan kesahan paten dimasukkan dalam kontrak lesen. Hal ini mengundang persoalan sama ada klausa tersebut dibenarkan oleh undang-undang persaingan atau tidak kerana tidak diperincikan dengan jelas dalam Garis Panduan Hak Harta Intelek dan Undangundang Persaingan. Bagi Kesatuan Eropah misalnya, klausa seperti ini tidak dianggap sebagai antipersaingan namun tidak termasuk dalam pengecualian blok. ${ }^{10}$ Suruhanjaya Persaingan Eropah berpendapat bahawa pemegang lesen berada dalam kedudukan yang terbaik untuk menentukan kesahan hak harta intelek tertentu selain memastikan agar hak harta intelek yang tidak sah dihapuskan kerana menghalang perkembangan inovasi. Namun begitu, klausa seperti ini berkemungkinan bersifat antipersaingan sekiranya melibatkan pelesenan teknologi yang sangat bernilai dan menimbulkan kerugian persaingan bagi perusahaan yang dihalang menggunakannya atau hanya dapat menggunakan teknologi tersebut sekiranya bayaran royalti dibuat. Walau bagaimanapun, sekiranya klausa yang mensyaratkan pemegang lesen paten menjauhi semua tindakan yang mampu menjejaskan kesahan paten disertakan dengan klausa yang memberikankebebasankepadapemeganglesenuntukmenamatkan kontrak lesen, maka, Suruhanjaya Persaingan Eropah berpandangan bahawa ia tergolong dalam skop pengecualian blok. Hal ini dinyatakan dengan jelas melalui perenggan 134 hingga 140 oleh peraturan yang dikenali sebagai Guidelines on the Application of Article 101 of the Treaty on the Functioning of the European Union to Technology Transfer Agreements.

Dalam kes Genentech Inc v. Hoechst $\mathrm{GmbH},{ }^{11}$ isu yang dibangkitkan adalah sama ada kewajipan pembayaran yuran lesen dalam bentuk royalti

10 Pengecualian Blok atau dikenali sebagai Block Exemption ialah pengecualian yang diberikan kepada beberapa kategori perjanjian, salah satunya ialah perjanjian berkaitan dengan harta intelek yang menepati syarat yang terkandung dalam Artikel 101(3) Treaty on the Functioning of the European Union ( TFEU).

11 Kes C-567/14 Genentech Inc v. Hoechst GmbH, judgment of 7 July 2016, https:// eur-lex.europa.eu/legal-content/EN/TXT/?uri=CELEX\%3A62014CJ0567 (akses 21 April 2021). 
perlu diteruskan walaupun paten yang dilesenkan telah dibatalkan atau berlaku pelanggaran hak paten. Mahkamah dalam kes ini berpandangan bahawa klausa berkaitan dengan pembayaran yuran lesen (royalti) dalam kontrak lesen tetap harus dibayar dan tidak bersifat antipersaingan dengan syarat pemegang lesen diberikan kebebasan untuk menamatkan kontrak lesen dengan memberikan notis yang munasabah.

Perkara ini juga turut dinyatakan dalam laporan Kajian Pasaran bagi Sektor Farmaseutikal yang mendapati kebanyakan pemegang lesen enggan mencabar kesahan sesuatu paten walaupun terdapat alasan yang sah dan kukuh untuk berbuat demikian kerana kos yang tinggi diperlukan untuk membawa kes sedemikian ke Mahkamah (Kajian Pasaran bagi Sektor Farmaseutikal, 2017: 146).

Jika ditinjau amalan di United Kingdom yang juga mengandungi peruntukan serupa berkaitan dengan klausa tidak sah dalam seksyen 44 UK Patents Act 1977, peruntukan tersebut telah dimansuhkan sejurus selepas undang-undang persaingan diperkenalkan di United Kingdom melalui UK Competition Act 1998. Pemansuhan tersebut bertujuan untuk mengelakkan pertindihan bidang kuasa kedua-dua rejim undang-undang, iaitu undang-undang persaingan dan undang-undang paten di United Kingdom dan menyerahkannya kepada UK Competition Act 1998 untuk mengambil tindakan terhadap pemilik paten yang melakukan aktiviti yang bersifat antipersaingan (Lai, \& Kathuria, 2018: 260). Namun begitu, buat masa ini, seksyen 45 Akta 291 masih lagi berkuat kuasa dan terpakai untuk perkara berkaitan dengan paten di Malaysia.

Selain itu, terdapat keperluan untuk memberikan pengecualian blok bagi urusan berkaitan dengan harta intelek walaupun Garis Panduan Hak Harta Intelek dan Undang-undang Persaingan telah ada. Amalan ini bukanlah sesuatu yang baharu kerana telah dilaksanakan oleh Kesatuan Eropah melalui peraturan yang dikenali sebagai Technology Transfer Block Exemption Regulations ataupun nama ringkasnya TTBER. Pengecualian blok yang diberikan untuk urusan berkaitan dengan pemindahan teknologi yang melibatkan harta intelek bertujuan untuk mengurangkan jumlah permohonan pengecualian individu yang memerlukan semakan Suruhanjaya Persaingan Eropah (Gonzalez, 1983: 251) di samping memastikan keseragaman pelaksanaan undangundang persaingan terhadap harta intelek. Tambahan pula, harta intelek memenuhi syarat-syarat yang membolehkannya diberikan pengecualian blok yang terkandung dalam Artikel 101(3) TFEU. 
Dalam hal ini, Akta 712 juga mengandungi peruntukan serupa berkaitan dengan pengecualian blok, iaitu dalam seksyen 8 yang menyatakan bahawa pengecualian boleh diberikan dengan syarat perjanjian antipersaingan tersebut memenuhi keperluan yang ditetapkan dalam seksyen 5 Akta 712. Untuk makluman, syarat-syarat yang terkandung dalam seksyen 5 Akta 712 juga serupa dengan syarat yang terkandung dalam Artikel 101(3) TFEU. Namun begitu, setakat ini, MyCC hanya memberikan pengecualian blok bagi Perjanjian Perkongsian Vesel Berkenaan dengan Perkhidmatan Pelayaran Tetap melalui Pengangkutan Laut yang bermula pada 7 Julai 2019 dan tamat pada 6 Julai 2022.

\section{KESIMPULAN}

Perbincangan di atas menunjukkan bahawa undang-undang persaingan di Malaysia telah berkembang sejak diperkenalkan pada tahun 2010 sehingga kini. Peningkatan kes pelanggaran yang diputuskan oleh MyCC, Tribunal Rayuan Persaingan dan permohonan semakan kehakiman di Mahkamah Tinggi meningkat setiap tahun menunjukkan bahawa MyCC memandang serius pelanggaran peruntukan berkaitan dengan larangan yang terkandung dalam Akta 712. Dari perspektif harta intelek pula, tindakan MyCC memperkenalkan Garis Panduan Hak Harta Intelek dan Undangundang Persaingan merupakan satu tindakan yang tepat pada masanya. Tanpa garis panduan khusus berkaitan dengan harta intelek, pelaksanaan undang-undang persaingan terhadap pemilik harta intelek tidak dapat dibuat secara efektif kerana mekanisme yang digunakan oleh undangundang harta intelek dilihat berbeza dengan mekanisme yang diguna pakai oleh undang-undang persaingan walaupun kedua-duanya terarah pada objektif yang sama, iaitu meningkatkan kesejahteraan pengguna. Perbezaan mekanisme yang diguna pakai oleh kedua-dua undang-undang tersebut menuntut agar garis panduan khusus berkaitan dengan persaingan dan harta intelek dibangunkan supaya skop pelaksanaan undang-undang persaingan terhadap harta intelek dapat dijelaskan. Walaupun belum ada kes berkaitan dengan harta intelek yang diputuskan oleh MyCC, namun pengenalan Garis Panduan Hak Harta Intelek dan Undang-undang Persaingan merupakan satu langkah proaktif yang dapat membantu pemilik harta intelek mengenal pasti kedudukan mereka di sisi undangundang persaingan dan membuat penilaian sama ada tingkah laku mereka melanggar Akta 712 atau tidak. Dalam masa yang sama, Garis Panduan 
Hak Harta Intelek dan Undang-undang Persaingan serta akta berkaitan dengan harta intelek, iaitu Akta Paten 1983 juga perlu ditambah baik dengan mengambil kira hasil Kajian Pasaran bagi Sektor Farmaseutikal untuk memastikannya jelas dan selaras dengan hasrat undang-undang persaingan yang memelihara kebajikan pengguna melalui persaingan adil dalam kalangan pengusaha.

\section{RUJUKAN}

Akta Paten 1983 (Akta 291).

Akta Perihal Dagangan 1972 (Akta 87).

Akta Perihal Dagangan 2011 (Akta 730).

Akta Perlindungan Pengguna 1999 (Akta 599).

Akta Persaingan 2010 (Akta 712).

Akta Suruhanjaya Persaingan 2010 ( Akta 713).

Caro de Sousa, Pedro. (2018). The Interface of Competition and Intellectual Property Law - Taking Stock and Identifying New Challenges. Forthcoming in Liber Amicorum Frederic Jenny. SSRN. Diakses pada 8 Februari 2021 daripada https://ssrn.com/abstract=3279355 or http://dx.doi.org/10.2139/ ssrn.3279355

Garis Panduan Bab 1 Larangan: Perjanjian AntiPersaingan. MyCC. Diakses pada 8 Februari 2021 daripada http://www.mycc.gov.my/guideline.asp

Garis Panduan Bab 2 Larangan: Penyalahgunaan Kedudukan Dominan. MyCC. Diakses pada 8 Februari 2021 daripada http://www.mycc.gov.my/guideline. asp

Garis Panduan Definisi Pasaran. MyCC. Diakses pada 8 Februari 2021 daripada http://www.mycc.gov.my/guideline.asp

Garis Panduan Hak Harta Intelek dan Undang-Undang Persaingan. MyCC. Diakses pada 8 Februari 2021 daripada http://www.mycc.gov.my/guideline. asp

Garis Panduan Penalti Kewangan. MyCC. Diakses pada 8 Februari 2021 daripada http://www.mycc.gov.my/guideline.asp

Garis Panduan Prosedur Aduan. MyCC. Diakses pada 8 Februari 2021 daripada http://www.mycc.gov.my/guideline.asp

Garis Panduan Rejim Kelonggaran. MyCC. Diakses pada 8 Februari 2021 daripada http://www.mycc.gov.my/guideline.asp

Gerber, D. J. (2010). Global competition: Law, markets, and globalization. Oxford University Press.

Gilbert, Richard \& Shapiro, Carl. (1997). Antitrust Issues in the Licensing of Intellectual Property: The Nine No-No's Meet the Nineties. Brookings Papers on Economic Activity: Microeconomics, hlm. 283. 
Gonzalez, J. E. (1983). Technology transfers in the ECC: A look at the proposed block exemption for exclusive patent licensing agreements. Fordham International Law Journal, 7(2), hlm. 244, 1983.

Janis, M. D. (2005). Minimal' standards for patent-related antitrust law under TRIPS, in K.E. Maskus \& J.H. Reichman (Eds.), International public goods and transfer of technology under a globalized intellectual property regime. Cambridge University Press.

Maskus, K. E. (2001). Intellectual property challenges for developing countries: An economic perspective. University of Illinois Law Review, 472.

Khadijah Mohamed. (2020). The interface between intellectual property rights and competition law: Legal development in malaysia. WIPO-WTO Colloquium Papers. Research Papers From The WIPO-WTO Colloquium For Teachers Of Intellectual Property Law. Diakses pada 8 Februari 2021 daripada https://www.wto.org/english/tratop_e/trips_e/colloquium_papers_e/2019/ chapter_10_2019_e.pdf

Lai, J. C., \& Kathuria, V. (2018). Restrictive conditions in patent law and the competition law interface. Journal of World Intellectual Property 21, (3-4), 256.

Leslie, C. R.. (2011). Antitrust law and intellectual property rights, cases and materials. Oxford University Press.

M. Furse, (2008). Competition law of the EC and UK. Sixth Edition. Oxford University Press.

Market Review on Priority Sector under Competition Act 2010 (Pharmaceutical Sector). MyCC. Diakses pada 21 April 2021 daripada https://www.mycc. gov.my/sites/default/files/pdf/newsroom/Market\%20Review\%20on\%20 Pharmaceutical\%20Sector.pdf

Nasaruddin Abdul Rahman \& Haniff Ahamat. (2016). Competition law in Malaysia. Sweet \& Maxwell.

Nine-No-Nos, United States Department of Justice. Diakses pada 20 April 2021 daripada https:/www.justice.gov/opa/speech/times-they-are-achangin-nineno-nos-2019

Stakheyeva, H. (2018). Intellectual property and competition law: Understanding the interplay. Bharadwaj A., Devaiah V., Gupta I. (Eds.), Multi-dimensional Approaches Towards New Technology. Springer.

Tu Thanh Nguyen. (2010). Competition law,technology transfer and the TRIPS agreement implications for developing countries. Edward Elgar Publishing Limited.

United Nations. (2016). Examining the interface between the objectives of competition policy and intellectual property. Nota sekretariat UNCTAD. United Nations Conference on Trade Developments. Diakses pada 8 Februari 2021 daripada https://unctad.org/system/files/official-document/ciclpd36_ en.pdf 
Yijun Tian. (2009). Intellectual property (IP) protection versus IP abuses: The recent development of Chinese IP abuse rules and recommendations for foreign technology-driven companies. Computer Law \& Security Review, 25,354 . 